Águas Subterrâneas (2017) 31(2):58-73.

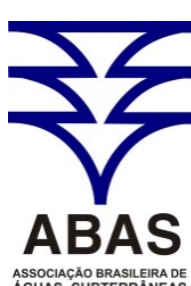

ASSOCIACÁO BRASLLERADE www.abas.org

\title{
AVALIAÇĀO FISICO-QUIMICA DAS AGUAS DO PROCESSO DE DESSALINIZAÇÃO DE POÇOS SALOBROS E SALINOS EM COMUNIDADES RURAIS DO OESTE POTIGUAR
}

\author{
PHYSICAL-CHEMICAL ASSESSMENT OF THE WATERS FROM \\ DESSALINIZATION PROCESS OF SALOBROS AND SALINOS WELLS IN RURAL \\ COMMUNITIES OF THE WEST POTIGUAR
}

\begin{abstract}
André Moreira de Oliveira ${ }^{1}$; Nildo da Silva Dias ${ }^{1}$; Jair José Rabelo de Freitas ${ }^{1}$; Daniel Freitas Freire Martins ${ }^{1}$; Lycia Nascimento Rabelo ${ }^{2}$
\end{abstract}

Artigo recebido em: 14/10/2016 e aceito para publicação em: 06/03/2017.

DOI: http://dx.doi.org/10.14295/ras.v31i2.28663

\begin{abstract}
Resumo: O fornecimento de água potável é o maior desafio das comunidades rurais da região semiárida do Brasil, que são caracterizadas pela escassez de recursos hídricos apropriados para consumo humano. Em uma tendência observada há alguns anos, os Governos Federal e Estadual têm buscado instalar equipamentos de dessalinização das águas salobras subterrâneas para a geração de água doce para o abastecimento de comunidades distantes dos centros urbanos. Desta forma, o objetivo deste trabalho foi avaliar a qualidade das águas oriundas do processo de dessalinização de poços em comunidades rurais do oeste potiguar e seus riscos quanto ao uso na irrigação. A pesquisa foi realizada no período de 2013 e 2014 e, inicialmente, foram identificadas as comunidades abastecidas com as unidades de captação e tratamento de água por dessalinização, através de um levantamento cadastral. Para isto, foram realizadas quatro campanhas de coletas em diferentes períodos do ano para avaliação da qualidade das águas potável do tratamento por osmose reversa, poço e rejeito salino, dentro de cada período. Foram analisados parâmetros físico-químicos das águas para fins de irrigação. As águas foram classificadas quanto ao uso na irrigação; aos riscos de problemas de infiltração no solo causados pela sodicidade da água e toxicidade em plantas. As estações de tratamento de água por osmose reversa nas comunidades rurais monitoradas produziram uma água dessalinizada com concentrações baixas de sais, com $68 \%$ do total das amostras na classe de classificação $\mathrm{C}_{1} \mathrm{~S}_{1}$; $25 \%$ na classe $\mathrm{C}_{2} \mathrm{~S}_{1}$ e; apenas $7 \%$ na classe $\mathrm{C}_{3} \mathrm{~S}_{1}$. Com relação ao rejeito gerado, 93\% das amostras de água de rejeito se classificaram como $\mathrm{C}_{3}$ ou $\mathrm{C}_{4}$ nos quatro períodos de coleta, ou seja, águas de alto ou extremamente alto risco de salinização.
\end{abstract}

Palavras-chave: Salinidade. Osmose reversa. Água residuária.

Abstract: The supply of drinking water is the biggest challenge of rural communities in semiarid region of Brazil, which are characterized by the scarcity of water resources suitable for human consumption. A trend a few years ago, the federal and state governments have sought to install desalination equipment of underground brackish water to generate fresh water to supply more distant communities from urban centers. Thus, the objective of this study was to evaluate the quality of water wells desalination process in rural communities from Potiguar West. This research was conducted between 2013 and 2014. At first, the communities which were supplied by catchment and treatment of desalinated water centers were registered through a cadastral survey. In order to do so, four data collection expeditions took place in different periods as well as the evaluation of a) the reverse osmosis treated water quality, b) the well, c) the reject brine Physicochemical attributes of water for irrigation was also analyzed. The waters were classified according to its use for irrigation; leakage risks and toxicity in plants In the monitored rural communities, the reversed osmosis water treatment stations produce desalinated water with low concentrations of salts, with $68 \%$ of all samples are in $\mathrm{C}_{1} \mathrm{~S}_{1}$ rating class; $25 \%$ in $\mathrm{C}_{2} \mathrm{~S}_{1}$ and class; only $7 \%$ in $\mathrm{C}_{3} \mathrm{~S}_{1}$ class. Regarding the reject brine, $93 \%$ of waste water samples were classified as $\mathrm{C}_{3}$ or $\mathrm{C}_{4}$ during the four collecting periods, that is, at high or extremely high salinization risk.

Keywords: Salinity. Reverse osmosis. Wastewater.

\footnotetext{
${ }^{1}$ Universidade Federal Rural do Semi-Árido (UFERSA). E-mails: (andremoreira@ufersa.edu.br, nildo@ufersa.edu.br, jair_ufersa@yahoo.com.br, dffm@ufersa.edu.br )

2 Universidade Federal do Rio Grande do Norte (UFRN). E-mails: (lycia_nascimento@hotmail.com)
} 


\section{INTRODUÇÃO}

No semiárido do Nordeste brasileiro se depara clara a relação com o excesso e a carência de água, afetando o comportamento da biota e das comunidades que vivem nessa região. Os problemas existentes comumente estão vinculados em colocar em funcionamento as políticas públicas direcionadas a gestão dos recursos hídricos. Diferentes políticas públicas com base em uma solução tecnológica específica têm passado pelo semiárido como ondas: a pequena açudagem, os poços com dessalinizadores e as cisternas são algumas delas (ANA, 2012).

A causa da escassez de água no Nordeste reside, à princípio, na baixa pluviosidade e irregularidade das chuvas da região, o que, de certa forma, interfere inclusive no volume de água dos rios. Muitas vezes a água apresenta salinidade elevada, impossibilitando o seu uso para consumo humano (LAMARCA, 2013).

Mesmo com a deficiência de recursos hídricos superficiais, poderiam ser extraídos do subsolo da região Nordeste, sem possibilidade de colapso dos mananciais, pelo menos 19,5 bilhões de $\mathrm{m}^{3}$ de água subterrânea (SOARES, 2007). No entanto, ainda de acordo com Soares (2007), o uso destas águas subterrâneas é restrito devido aos problemas dos poços situados no interior nordestino, que é a concentração elevada de sais.

Não obstante, Amorim (2004) ressalta que o problema da salinização dos mananciais não torna estes recursos inexploráveis já que, a tecnologia da dessalinização permite a viabilização dos mesmos no Nordeste do Brasil, onde vem sendo empregada a tecnologia da osmose reversa, possibilitando a sua utilização para consumo humano.

Quando se fala em expansão do uso da osmose reversa, um dos fatores que preocupa diz respeito aos rejeitos gerados no processo de dessalinização, pois, independentemente da eficiência da membrana e da estrutura instalada dos dessalinizadores, o sistema de osmose reversa produzirá sempre a água potável, mas também a água residuária (rejeito salino); estimada em aproximadamente 50$60 \%$ da água bruta inicialmente tratada por osmose reversa, com concentração de sais superior à salinidade da água original.

Dessa forma, o grande desafio da utilização do sistema de tratamento de água com osmose reversa reside na disposição ou reutilização da água de rejeito de forma a evitar impactos negativos ao ambiente, pois comumente são derramados em cursos d'água e no solo sem qualquer avaliação.

No Oeste Potiguar há um número elevado de dessalinizadores instalados e conforme as informações providas pelos operadores dos dessalinizadores de algumas comunidades da região, o rejeito produzido é, em média, de $8 \mathrm{~m}^{3} \mathrm{dia}^{-1}$ - e considerando que existem em torno de 60-70 dessalinizadores funcionando nesta região, segundo informações fornecidas pela Secretaria de Estado do Meio Ambiente e Recursos Hídricos do Rio Grande do Norte (SEMARH, 2013), $440 \mathrm{~m}^{3} \mathrm{dia}^{-1}$ de rejeito estão sendo despejados diariamente no solos ou corpos hídricos sem nenhum tipo de tratamento.

Nesse contexto, considerando esses e outros aspectos, objetivou-se avaliar os riscos de salinização do solo, problemas com infiltração e a toxicidade de íons específicos das águas salobras de poços, de rejeito salino provenientes de estações de tratamento e a água potável da dessalinização em diferentes períodos do ano em sete comunidades rurais do Oeste Potiguar;

\section{MATERIAL E MÉTODOS}

O clima predominante da região Oeste Potiguar, segundo classificação de Köppen é do tipo BSw’h', caracterizado por ser muito quente e semiárido, com a estação chuvosa se atrasando para o outono, levando a dois períodos distintos: um de chuvas, denominado de inverno, com duração aproximada de quatro meses, e outro de estiagem, nos oito meses restantes. O período de chuvas se situa comumente entre os meses de fevereiro a maio, sendo os meses de março 
e abril os de maior precipitação e os demais secos. A temperatura média anual dos municípios é em torno de $27-29{ }^{\circ} \mathrm{C}$ e precipitação pluvial anual média de cerca de 550-750 mm.

A área abrange características de paisagem e clima similares, com vegetação dominante a caatinga hiperxerófila, de natureza mais seca e porte baixo, adaptada a escassez e baixa umidade do ar, o que proporciona revestimento em geral de cor acinzentada e com alta diversidade em tipos de solos.

A coleta das amostras foi realizada no período de 2013 a 2014 em comunidades do Oeste Potiguar em que, inicialmente, foram identificadas e localizadas as comunidades da região abastecidas com unidades de captação e tratamento de água por dessalinização. O levantamento cadastral das comunidades foi realizado por meio de consulta na Secretaria de Recursos Hídricos do Estado do Rio Grande do Norte (SEMARH).

Nas comunidades, foram realizadas entrevistas com os líderes das comunidades para obtenção de informações sobre as descrições técnicas dos poços. De uma forma geral, os poços apresentam profundidade entre 50 e 150 metros; parcialmente revestidos (10 a 15 metros iniciais); tempo de exploração superior a cinco anos; vazão entre 4 e $5 \mathrm{~m}^{3} \mathrm{~h}^{-1}$ e operação máxima diária de oito horas.

Diante desse levantamento, considerando as características favoráveis ao monitoramento (manutenções adequadas; semelhança entre os poços; utilização diária do dessalinizador), foram selecionadas sete comunidades rurais do oeste potiguar (Figura 1).

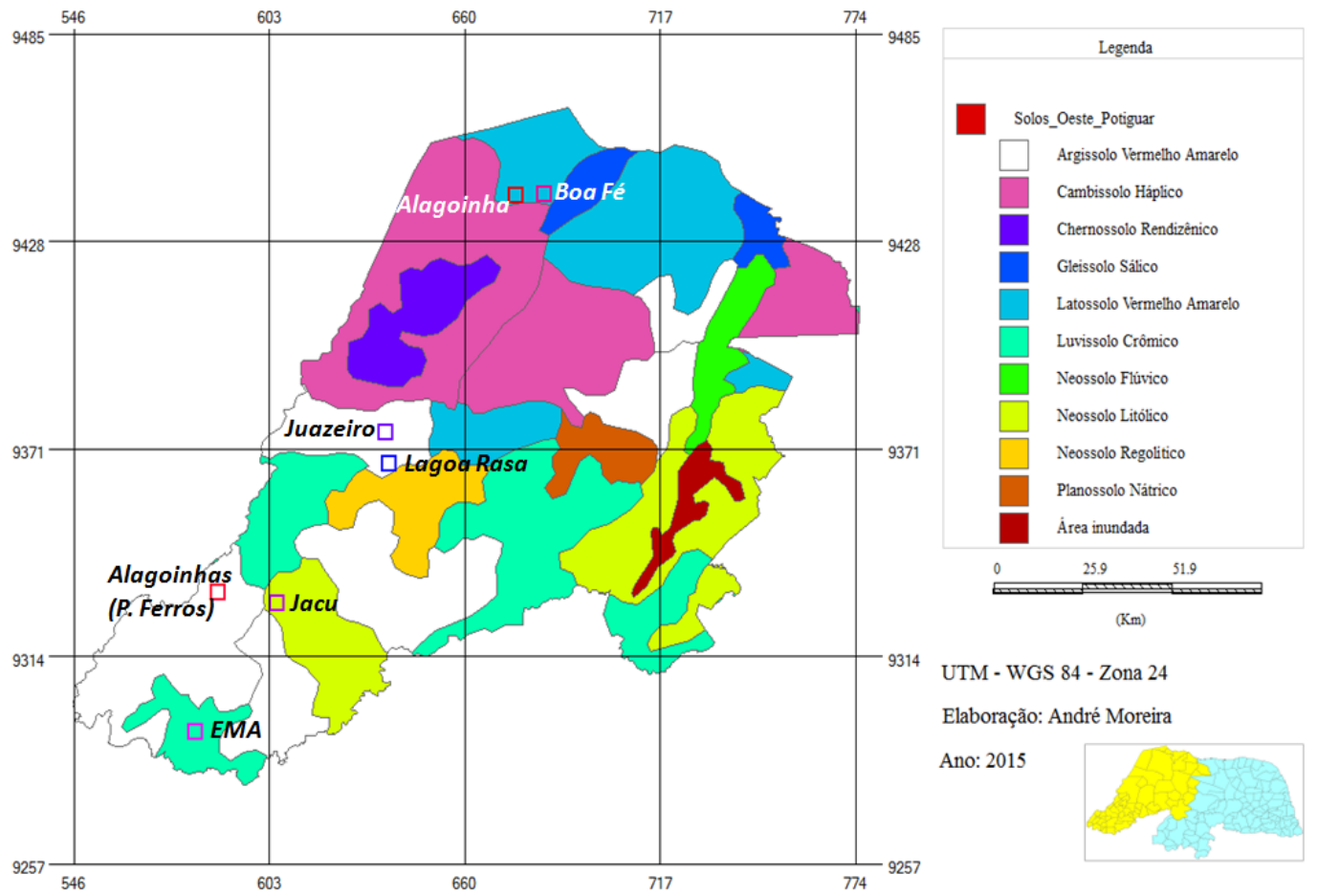

Figura 1 - Mapa de solos (IBGE) da área experimental com a localização dos pontos coletados Fonte: Adaptado pelo autor de IBGE (2015)

As coletas de amostras de água foram realizadas em quatro períodos, regularmente a cada três meses em cada área de estudo, de modo a retratar ou abranger todas as estações do ano, verificando as alterações físico- químicas da água dessalinizada e o efeito direto no solo: $\mathrm{P}_{1}=$ outubro/novembro (2013) - período seco, praticamente sem chuvas; $\mathrm{P}_{2}$ = fevereiro/março (2014), início do período chuvoso; $\mathrm{P}_{3}=$ junho/julho (2014), final do 
período chuvoso e $\mathrm{P}_{4}=$ outubro/novembro (2014), fechando o ciclo de doze meses, novamente no período seco.

A coleta dessas águas ocorria após ligar e aguardar o funcionamento, por cinco minutos do dessalinizador. As amostras de água foram acondicionadas em garrafas plásticas previamente esterilizadas, opacas, de $500 \mathrm{~mL}$, hermeticamente fechadas, armazenadas em caixa térmica com gelo, a fim de evitar ao máximo a atividade microbiológica e em seguida conduzidas para análise laboratorial.

As análises físico-químicas das amostras de água foram realizadas no Laboratório de Solo Água e Planta - LASAP, vinculado ao Departamento de Ciências Ambientais e Tecnológicas - DCAT da Universidade Federal Rural do Semi-Árido UFERSA, Câmpus Mossoró.

Nas amostras de água, para fins de irrigação, foram determinados os seguintes parâmetros: Condutividade Elétrica $\left(\mathrm{CE}_{\mathrm{a}} \mathrm{em}\right.$ $\left.\mathrm{dS} \mathrm{m}^{-1}\right)$, potencial hidrogeniônico $(\mathrm{pH})$, as concentrações de Sódio $\left(\mathrm{Na}^{+}\right)$, Cálcio $\left(\mathrm{Ca}^{2+}\right)$, Magnésio $\left(\mathrm{Mg}^{2+}\right)$, Potássio $\left(\mathrm{K}^{+}\right)$, Cloreto $\left(\mathrm{Cl}^{-}\right.$ ), Carbonato $\left(\mathrm{CO}_{3}{ }^{2-}\right)$ e Bicarbonato $\left(\mathrm{HCO}_{3}{ }^{-}\right)$, de acordo com as metodologias propostas por Richards (1954). Realizou-se, também, o cálculo da Razão de Adsorção de Sódio (RAS), para classificação das amostras quanto ao risco de sodificação e de problemas de infiltração no solo causados pela sodicidade da água.

Para classificar os riscos com problemas de infiltração, foi empregada a classificação proposta por Ayers \& Westcot (1999), restringindo-se a três classes de sodicidade, obtidas relacionando-se a RAS com a salinidade da água de irrigação, de acordo com a Tabela 1.

Tabela 1 - Riscos de problemas de infiltração no solo causados pela sodicidade da água

Classes de Sodicidade

\begin{tabular}{cccc} 
& \multicolumn{3}{c}{ Problemas } \\
\cline { 2 - 4 } RAS (mmol L $\left.)^{-1}\right)^{0,5}$ & $\mathrm{~S}_{1}$ & $\begin{array}{c}\mathrm{S}_{2} \\
\text { Crescentes } \\
\text { Sem }\end{array}$ & $\begin{array}{c}\mathrm{S}_{3} \\
\text { Severos }\end{array}$ \\
& & $\left.\mathrm{CE} \mathrm{dS} \mathrm{m}^{-1}\right)$ & \\
$0-3$ & $>0,70$ & $0,70-0,20$ & $<0,20$ \\
$3-6$ & $>1,20$ & $1,20-0,30$ & $<0,30$ \\
$6-12$ & $>1,90$ & $1,90-0,50$ & $<0,50$ \\
$12-20$ & $>2,90$ & $2,90-1,30$ & $<1,30$ \\
$20-40$ & $>5,00$ & $5,00-2,90$ & $<2,90$ \\
\hline
\end{tabular}

Fonte: Ayers \& Westcot (1999)

Para a classificação da água quanto ao risco de toxicidade, foram analisados os íons Sódio $\left(\mathrm{Na}^{+}\right)$e Cloreto $\left(\mathrm{Cl}^{-}\right)$proposto por Ayers \& Westcot (1999), considerando dois modos de aplicação e três classes (Tabela 2).

Os dados meteorológicos referentes à precipitação pluvial do período estudado, nos municípios que se localizavam as comunidades, foram os coletados pela Empresa de Pesquisa Agropecuária do Rio Grande do Norte - EMPARN, a fim de contribuir na discussão dos efeitos na lixiviação dos sais nos respectivos períodos (Figura 2). 
Tabela 2 - Concentrações de íons em água e respectivos riscos de toxicidade as plantas

\begin{tabular}{|c|c|c|c|c|}
\hline & \multirow{4}{*}{ Ílon } & \multirow{2}{*}{\multicolumn{3}{|c|}{$\begin{array}{c}\text { Classes de Toxicidade da Água } \\
\text { Problema }\end{array}$}} \\
\hline & & & & \\
\hline & & $\mathrm{T}_{1}$ & $\mathrm{~T}_{2}$ & $\mathrm{~T}_{3}$ \\
\hline & & Nenhum & Moderado & Severo \\
\hline \multirow{3}{*}{$\begin{array}{l}\text { Modo de } \\
\text { Aplicação }\end{array}$} & Sódio ou Cloreto $\left(\mathrm{mmol} \mathrm{L}^{-1}\right)$ & & & \\
\hline & Irrigação por superfície & $<3$ & $3-9$ & $>9$ \\
\hline & Irrigação por aspersão & $<3$ & $>3$ & - \\
\hline
\end{tabular}

Fonte: Ayers \& Westcot (1999)

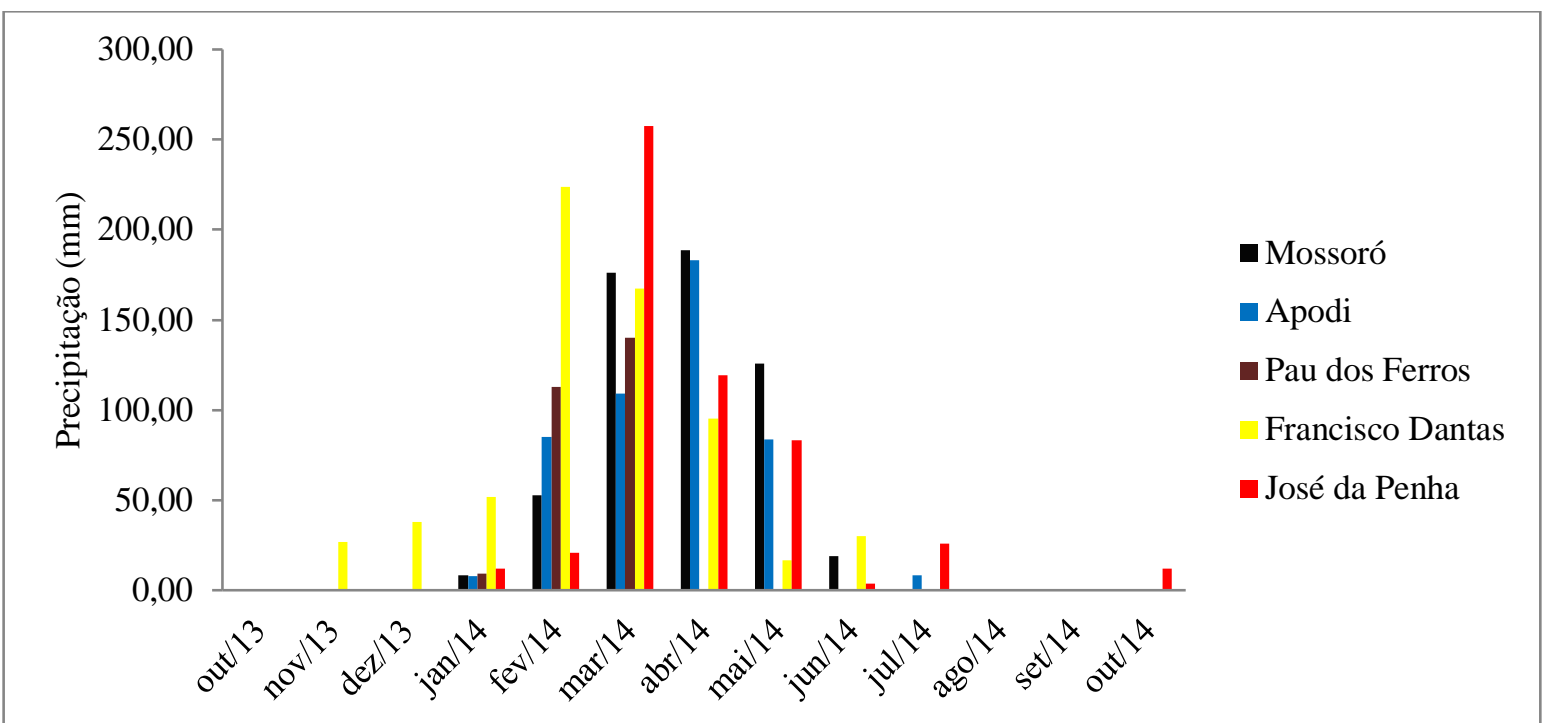

Figura 2 - Valores de precipitação (mm) nos períodos de coleta nos municípios onde estão localizadas as comunidades rurais estudadas

Fonte: Adaptado de EMPARN (2014)

As águas dos poços, dessalinizadas e dos rejeitos foram classificadas e interpretadas quanto os riscos de salinidade e sodicidade, de acordo com os parâmetros propostos por Richards (1954), utilizando-se um diagrama de classificação para cada tipo de água analisada, com auxílio do software Excel®.

Consideraram-se também, as diretrizes da Organização das Nações Unidas para Alimentação e Agricultura (FAO), para a avaliação da qualidade da água para irrigação (AYERS \& WESTCOT, 1999), especialmente, para os riscos de toxidez de íons específicos das amostras das águas visando sua utilização agrícola e manejo adequado da irrigação.

\section{RESULTADOS E DISCUSSÃO}

\section{1 Águas brutas (poço)}

Quanto ao risco potencial de salinização do solo pela técnica da irrigação, constatou-se que $49 \%$ das águas de poços foram classificadas na classe $\mathrm{C}_{3}$, sendo $42 \%$ como $\mathrm{C}_{3} \mathrm{~S}_{1}$ e $7 \%$ em $\mathrm{C}_{3} \mathrm{~S}_{2}$ (Tabela 3). A concentração salina $\left(\mathrm{C}_{3}\right)$, indica que é uma água com alto teor de sais, sendo necessário o uso de lavagem de manutenção (fração de lixiviação), além do uso de espécies vegetais com maior tolerância a salinidade. 35\% das amostras coletadas se classificaram na classe $\mathrm{C}_{4}$, o que indica uma água com salinidade muito alta, não sendo adequado para fins de irrigação, exceto para solos com alta permeabilidade, boa lixiviação, aplicação de excesso água e uso de plantas resistentes aos sais. 
OLIVEIRA, A.M.; DIAS, N.S.; FREITAS, J.J.R.; MARTINS, D.F.F. ; RABELO, L. N.

Tabela 3 - Análise química da água bruta das comunidades rurais em diferentes períodos

\begin{tabular}{|c|c|c|c|c|c|c|c|c|c|}
\hline Localidade & Período & $\begin{array}{c}\mathrm{pH} \\
\text { (água) }\end{array}$ & $\begin{array}{c}C E \\
\mathrm{dS} \mathrm{m}^{-1}\end{array}$ & $\begin{array}{c}\mathrm{Na}^{+} \\
--\mathrm{mmol}_{\mathrm{c}} \mathrm{L}^{-1}\end{array}$ & ${ }^{1} \mathrm{Cl}^{-}$ & RAS & USSL $^{-1}$ & $\mathrm{~S}^{2}$ & $\mathrm{~T}^{3}$ \\
\hline \multirow{4}{*}{ Lagoa Rasa } & $\mathrm{P} 1$ & 7,18 & 0,99 & 6,83 & 3,40 & 4,3 & C3S1 & $\mathrm{S} 2$ & $\mathrm{~T} 2$ \\
\hline & P2 & 7,47 & 1,10 & 7,30 & 4,20 & 4,2 & C3S1 & $\mathrm{S} 2$ & $\mathrm{~T} 2$ \\
\hline & P3 & 7,38 & 0,58 & 5,05 & 3,80 & 3,30 & C2S1 & $\mathrm{S} 2$ & $\mathrm{~T} 2$ \\
\hline & P4 & 7,50 & 0,95 & 13,42 & 4,40 & 9,15 & C3S2 & $\mathrm{S} 2$ & T3 \\
\hline \multirow{4}{*}{ EMA } & $\mathrm{P} 1$ & 7,49 & 2,16 & 11,29 & 15,20 & 5,4 & C3S2 & $\mathrm{S} 1$ & T3 \\
\hline & P2 & 7,39 & 2,60 & 15,14 & 13,20 & 6,7 & C4S2 & $\mathrm{S} 1$ & T3 \\
\hline & P3 & 7,30 & 1,98 & 37,79 & 12,20 & 16,9 & C3S4 & $\mathrm{S} 2$ & T3 \\
\hline & $\mathrm{P} 4$ & 7,50 & 1,93 & 35,72 & 12,80 & 15,7 & C3S4 & $\mathrm{S} 2$ & T3 \\
\hline \multirow{4}{*}{$\begin{array}{l}\text { Alagoinha } \\
\text { (Mossoró) }\end{array}$} & P1 & 7,72 & 1,09 & 2,67 & 6,20 & 1,4 & C3S1 & $\mathrm{S} 1$ & $\mathrm{~T} 2$ \\
\hline & P2 & 7,75 & 1,25 & 2,76 & 7,20 & 1,2 & C3S1 & $\mathrm{S} 1$ & $\mathrm{~T} 2$ \\
\hline & P3 & 7,40 & 1,09 & 5,66 & 6,20 & 2,90 & C3S1 & $\mathrm{S} 1$ & $\mathrm{~T} 2$ \\
\hline & $\mathrm{P} 4$ & 7,15 & 1,03 & 5,70 & 6,10 & 2,90 & C3S1 & $\mathrm{S} 1$ & $\mathrm{~T} 2$ \\
\hline \multirow{4}{*}{ Boa Fé } & P1 & 7,28 & 6,20 & 25,82 & 64,40 & 5,9 & C4S2 & $\mathrm{S} 1$ & T3 \\
\hline & P2 & 7,15 & 6,40 & 26,89 & 64,00 & 5,9 & C4S2 & $\mathrm{S} 1$ & T3 \\
\hline & P3 & 7,30 & 6,20 & 33,18 & 71,40 & 6,90 & C4S2 & $\mathrm{S} 1$ & T3 \\
\hline & P4 & 7,16 & 6,72 & 55,01 & 66,00 & 9,96 & C4S3 & $\mathrm{S} 1$ & T3 \\
\hline \multirow{4}{*}{ Jacu } & P1 & 7,53 & 2,54 & 8,49 & 23,20 & 3,2 & C4S1 & $\mathrm{S} 1$ & T3 \\
\hline & P2 & 6,13 & 2,60 & 8,38 & 23,60 & 3,1 & C4S1 & $\mathrm{S} 1$ & T3 \\
\hline & P3 & 7,00 & 0,17 & 0,71 & 2,40 & 0,64 & C1S1 & S3 & $\mathrm{T} 1$ \\
\hline & $\mathrm{P} 4$ & 7,10 & 2,30 & 20,49 & 22,00 & 6,25 & C4S2 & $\mathrm{S} 1$ & T3 \\
\hline \multirow{4}{*}{ Juazeiro } & P1 & 7,21 & 2,01 & 4,99 & 19,40 & 1,8 & C3S1 & $\mathrm{S} 1$ & T3 \\
\hline & P2 & 6,91 & 2,30 & 6,28 & 20,60 & 2,2 & C4S1 & $\mathrm{S} 1$ & T3 \\
\hline & P3 & 7,00 & 0,30 & 1,97 & 3,00 & 1,54 & C2S1 & $\mathrm{S} 2$ & $\mathrm{~T} 1$ \\
\hline & P4 & 7,08 & 1,95 & 11,46 & 30,00 & 3,42 & C3S1 & $\mathrm{S} 1$ & T3 \\
\hline \multirow{4}{*}{$\begin{array}{c}\text { Alagoinhas } \\
\text { (P. dos Ferros) }\end{array}$} & P1 & 7,38 & 2,10 & 7,44 & 10,60 & 2,7 & C3S1 & $\mathrm{S} 1$ & T3 \\
\hline & P2 & 7,25 & 2,30 & 7,56 & 14,20 & 1,4 & C4S1 & $\mathrm{S} 1$ & T3 \\
\hline & P3 & 8,20 & 0,57 & 10,13 & 4,00 & 6,11 & C2S1 & $\mathrm{S} 2$ & $\mathrm{~T} 2$ \\
\hline & P4 & 7,47 & 0,98 & 15,72 & 4,60 & 8,59 & C3S2 & S2 & T3 \\
\hline
\end{tabular}

${ }^{1}$ Diagrama de classificação de águas para irrigação da USSL (Richards, 1954).

${ }^{2}$ Riscos de problemas de infiltração no solo causados pela sodicidade da água (Ayers \& Westcot, 1999).

${ }^{3} \mathrm{Riscos}$ de toxicidade as plantas por íons de $\mathrm{Na}^{+}$ou $\mathrm{Cl}^{-}$na água de acordo com o modo de aplicação (Ayers \& Westcot, 1999).

Fonte: Autor (2016)

De acordo com as diretrizes da USSL (Figura 3), indiferente ao período do ano, somada as Classes $\mathrm{C}_{3}$ e $\mathrm{C}_{4}$ do total de amostras coletadas, $84 \%$ das amostras das águas dos poços apresentam CE superior à $0,75 \mathrm{dSm}^{-1}$, evidenciando a necessidade de fato, haver dessalinizadores nas comunidades, para, no mínimo, beneficiar o consumo humano. Destaca-se que todas as comunidades monitoradas neste estudo, apresentam um único poço como fonte de água pública e viável para extração.

Conforme a Figura 3, apenas 15\% das amostras, aproximadamente, foram classificadas em $\mathrm{C}_{1}$ (águas de salinidade baixa) ou $\mathrm{C}_{2}$ (águas de salinidade média) que são consideradas boas para a prática da irrigação, por apresentarem poucas restrições 
de uso, ou seja, baixo risco de desenvolverem problemas de salinidade.

$\mathrm{O}$ período em que os poços obtiveram as águas com maior $\mathrm{CE}$, fator principal na determinação da classe de acordo com diagrama proposto por Richards (1954), foi o período $\mathrm{P}_{2}$ (final do período seco / início do período chuvoso), em que quatro comunidades - EMA; Jacu; Juazeiro e Alagoinhas (P. Ferros) - tiveram suas águas brutas classificadas na classe $\mathrm{C}_{4}$. Assim como ocorreu o contrário, no período $\mathrm{P}_{3}$ (final do período chuvoso / início do período seco), onde as águas dos poços apresentaram de uma forma geral, uma CE mais baixa, com quatro poços de comunidades - Lagoa Rasa; Jacu; Juazeiro e Alagoinhas (P. Ferros) enquadradas nas classes $\mathrm{C}_{2}$ ou $\mathrm{C}_{1}$. Possivelmente esse fenômeno pode estar ligado aos ciclos de recarga e descarga dos mananciais, diluindo e concentrando os sais, proporcionado principalmente pelas chuvas da região (Figura 2).

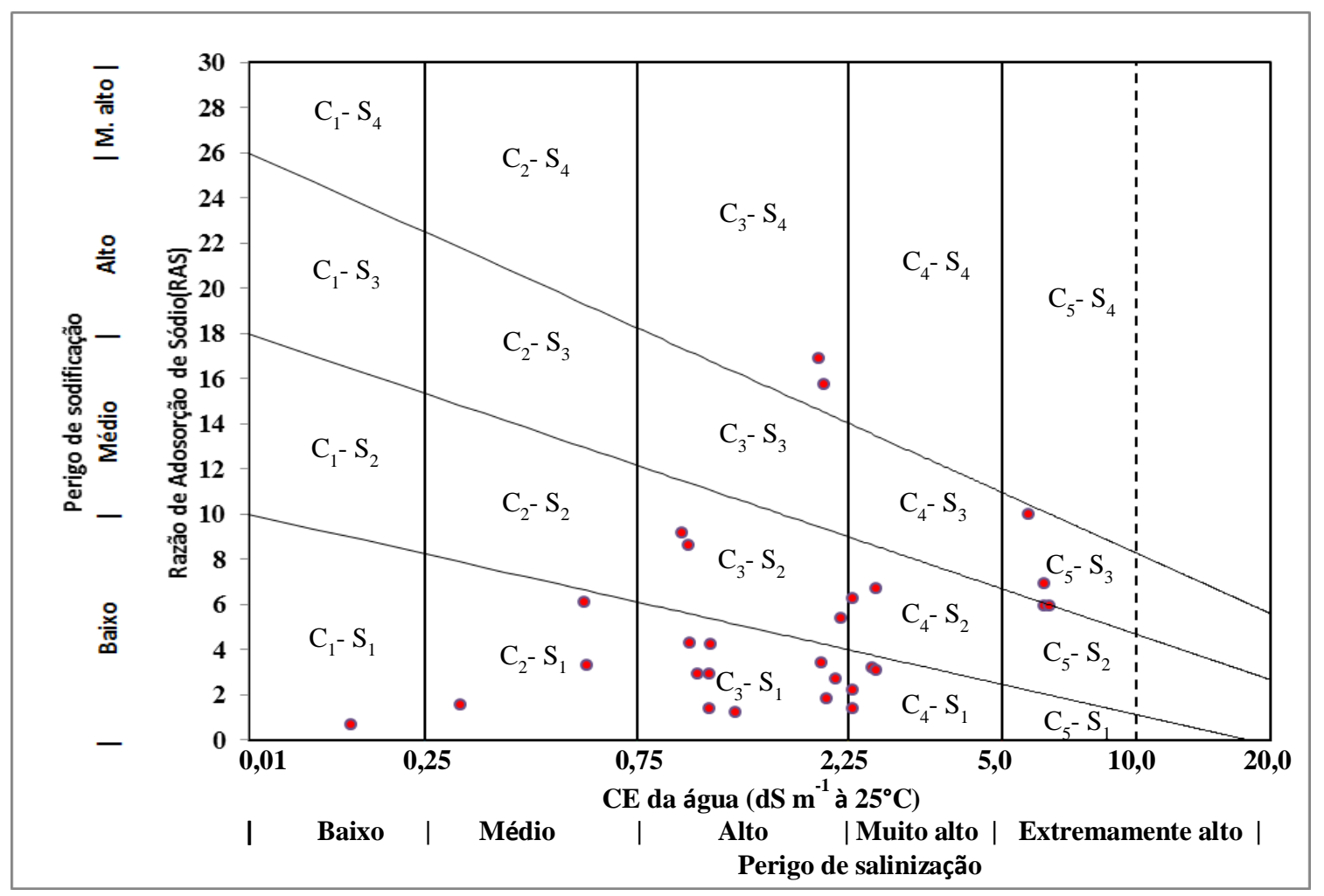

Figura 3 - Diagrama de classificação de águas para irrigação da USSL: classificação das águas brutas das comunidades rurais do Oeste Potiguar nos quatro períodos

Fonte: Autor (2016)

A redução da CE da água se deve a diluições dos sais com a recarga de aquífero e lençol freático, provocados pela infiltração das águas no solo durante os períodos chuvosos. Já nos períodos secos ocorre o inverso, a ausência de precipitação e a adsorção de íons das rochas nos aquíferos aumenta a concentração de sais na água. As rochas e os solos podem apresentar diferenças, mas os principais processos químicos e físicos são os mesmos. Medeiros (1992), estudando as águas utilizadas em pequenas irrigações nos estados do Ceará, Rio Grande do Norte e Paraíba, constatou que existem consideráveis variações nas suas características durante o ano, principalmente naquelas oriundas de poços amazonas e naturais, em leito de rios e pequenos e médios açudes.

Com a elevação de sais nas águas dos poços, há também alteração nas águas produtos da dessalinização por osmose reversa, onde a água dessalinizada, reduz a sua qualidade. As comunidades beneficiadas com o dessalinizador, a água dessalinizada é o 
principal produto, restringindo mais para o consumo doméstico, usadas principalmente para beber e cozinhar.

O outro produto deste processo, o rejeito da dessalinização, passa a ser ainda mais salino e agressivo quando despejado diretamente no solo. Conforme é verificado nas análises deste estudo nas sete comunidades monitoradas nos quatro períodos, ao comparar os valores da água bruta com as da água de rejeito (Tabela5), bem como os diagramas, percebe-se que os pontos que representam a água de rejeito (Figura 5) se concentraram nas faixas mais elevadas de risco de salinização e de sodificação que os pontos da água bruta.

Dentre as comunidades monitoradas, Boa Fé foi a que apresentou maiores valores de CE das águas de poço, variando entre 5,72 e $6,40 \mathrm{dS} \mathrm{m} \mathrm{m}^{-1}$, o que impede sua utilização, salvo em condições de técnicas de manejo, tais como: mistura de águas e utilização em sistemas hidropônicos. Oliveira (2011) cultivou hortaliças através de sistema hidropônico em fibra de coco, com águas da estação do dessalinizador desta comunidade com poucas perdas de produtividade, evidenciando potencial de utilização destas águas.

Verificando o $\mathrm{pH}$ das águas brutas de todas as comunidades nos quatro períodos, constatou-se que $86 \%$ das amostras tiveram valores de $\mathrm{pH}$ entre 7,00 e 7,50 (neutro à moderadamente alcalino). De acordo com a Portaria $n^{\circ}$ 2914/2011 - MS estes valores de pH estão nas condições e padrões para consumo humano, em que permite variação entre 6,0 e 9,5. Segundo Ayers e Westcot (1999), os valores do $\mathrm{pH}$ observados durante o monitoramento, encontram-se dentro da faixa de normalidade, para fins de irrigação $(6,5$ a 8,5), ressaltando-se que a água pode ser utilizada, sem restrição em sistemas de irrigação, devido à baixa amplitude desses índices, evitando riscos de desequilíbrio nutricional às culturas.

De acordo com a classificação para riscos de problemas de infiltração nos solos causados pela sodicidade da água, proposto por Ayers \& Westcot (1999), 64\% das amostras de água bruta foram classificadas como $S_{1}$, ou seja, sem riscos de problemas de infiltração. Mesmo com parte das amostras apresentando elevados valores de RAS, ainda assim se enquadraram na classe sem risco. Isto se deve a $\mathrm{CE}_{\mathrm{a}}$ da água com maior valor, pois os sais da solução do solo tem um efeito floculante, oposto ao efeito dispersante do sódio trocável. Dessa forma, para uma mesma RAS o risco de sodicidade será menor quanto maior for a $\mathrm{CE}_{\mathrm{a}}$ (HOLANDA, 2010).

Considerando as demais amostras, 9\% foram classificadas em $\mathrm{S}_{2}$, o que caracteriza com riscos crescentes de infiltração no solo, necessitando de um manejo criterioso no uso destas águas a fim de evitar problemas de difícil reparação, como o encrostamento superficial do solo. Destaca-se as águas do poço da comunidade de Lagoa Rasa no município de Apodi, que durante toda a campanha de coletas, teve suas águas classificadas como $\mathrm{S}_{2}$, embora tenha oscilado significativamente os sais da água.

O período de coletas nos meses de Junho e Julho $\left(\mathrm{P}_{3}\right)$ foi o que obteve o maior número de amostras qualificadas com riscos de sodicidade, exceto para as comunidades de Alagoinha e Boa fé, comunidades pertencentes ao município de Mossoró, ambas por terem mantido a CE da água semelhante em todos os períodos, inibindo o efeito da RAS que oscilou nos diferentes períodos.

Na comunidade de Jacu, no período $\mathrm{P}_{3}$, a amostra de água do poço foi classificada como $\mathrm{S}_{3}$, isto é, de risco severo para problemas de infiltração, ainda que com RAS mais baixa $(0,64)$ entre as comunidades estudadas. Justificando esta classificação pela também baixa $\mathrm{CE}_{\mathrm{a}}$, a qual fortalece a ação do sódio como agente dispersante nas micelas do solo quando depositada no sistema solo.

Quanto à classificação da água para o risco de toxicidade pelas concentrações de íons de sódio ou cloreto, proposto por Ayers \& Westcot (1999), 64\% das amostras de água bruta foram classificadas como $\mathrm{T}_{3}$, de risco severo de toxicidade às plantas, seja por sistema de irrigação por superfície ou por aspersão, o que proporcionaria grandes perdas na produtividade ou até mesmo morte das 
plantas a depender da tolerância da cultura. As comunidades de Boa Fé e Ema obtiveram suas águas com essa classificação para todos os períodos do ano, com elevados níveis de sódio e cloreto, sendo a água bruta destas respectivas comunidades consideradas inaptas para o uso via sistema de irrigação em plantas.

Apesar dos poços das comunidades rurais pesquisadas neste estudo apresentarem algumas características semelhantes, muitos atributos podem torna-los distintos: quantidade de poços perfurados nas imediações; vazão; qualidade no revestimento das paredes do poço; entre outros. Segundo Hirata (2001), a qualidade da água subterrânea pode ser avaliada através da associação de vários fatores intrínsecos, são alguns deles: a forma de ocorrência da água subterrânea (tipo de aquífero); arcabouço litológico que sustenta o aquífero na zona não saturada ea profundidade do nível da água.

Para as demais amostras, 29\% se enquadraram na classe $T_{2}$, cujo risco é moderado para o uso na irrigação por superfície ou aspersão. Apenas 7\% do total de amostras não apresentam riscos de toxicidade no uso na irrigação. De um modo geral, a água bruta de todas as comunidades classificou-se com risco moderado ou severo em quase todos os períodos, sendo o período com maior número de restrição $\mathrm{o} \mathrm{P}_{4}$, com seis comunidades com águas classificadas com risco severo $\left(\mathrm{T}_{3}\right)$. Esses dados fortalecem a necessidade da implantação de dessalinizadores nas comunidades, se imprópria para o uso em irrigação para cultivo de plantas, ainda mais restrito para o consumo humano.

\section{2 Águas dessalinizadas}

A dessalinização das águas nas comunidades rurais da região Oeste Potiguar, assim como na grande maioria das comunidades beneficiadas com dessalinizadores no nordeste brasileiro, tem como interesse principal a obtenção de água potável para consumo humano, visando o uso doméstico. Mesmo assim, estas águas podem também ser classificadas quanto sua qualidade para irrigação, visando à possibilidade de sua utilização na agricultura. Este fato é muito comum em vários países do Oriente-Médio como Arábia Saudita e Israel, além da Espanha, onde 22,4\% do total de água dessalinizada são usados para agricultura (BELTRÁN \& KOO- OSHIMA, 2006).

Observando o diagrama da USSL evidenciado na Figura 4 para as amostras de água dessalinizadas das comunidades rurais estudadas, verifica-se que os dessalinizadores instalados nas comunidades produzem uma água com concentrações baixas de sais, percebendo que $68 \%$ do total das amostras estão na classe de classificação $\mathrm{C}_{1} \mathrm{~S}_{1} ; 25 \%$ na classe $\mathrm{C}_{2} \mathrm{~S}_{1} \mathrm{e}$; apenas $7 \%$ na classe $\mathrm{C}_{3} \mathrm{~S}_{1}$.

De acordo com esta classificação, 93\% das amostras de água dessalinizadas são águas boas para o uso na irrigação, ou seja, praticamente sem necessidade de práticas especiais de controle de salinidade $\left(\mathrm{C}_{1}\right.$ e $\left.\mathrm{C}_{2}\right)$. Vale considerar, que mesmo com o processo de dessalinização a CE da água de algumas comunidades foi superior a $0,25 \mathrm{dSm}^{-1}$, como observado na comunidade Boa Fé, que apenas em um dos períodos apresentou $\mathrm{CE}_{\mathrm{a}}$ abaixo desse valor (Tabela 4). 


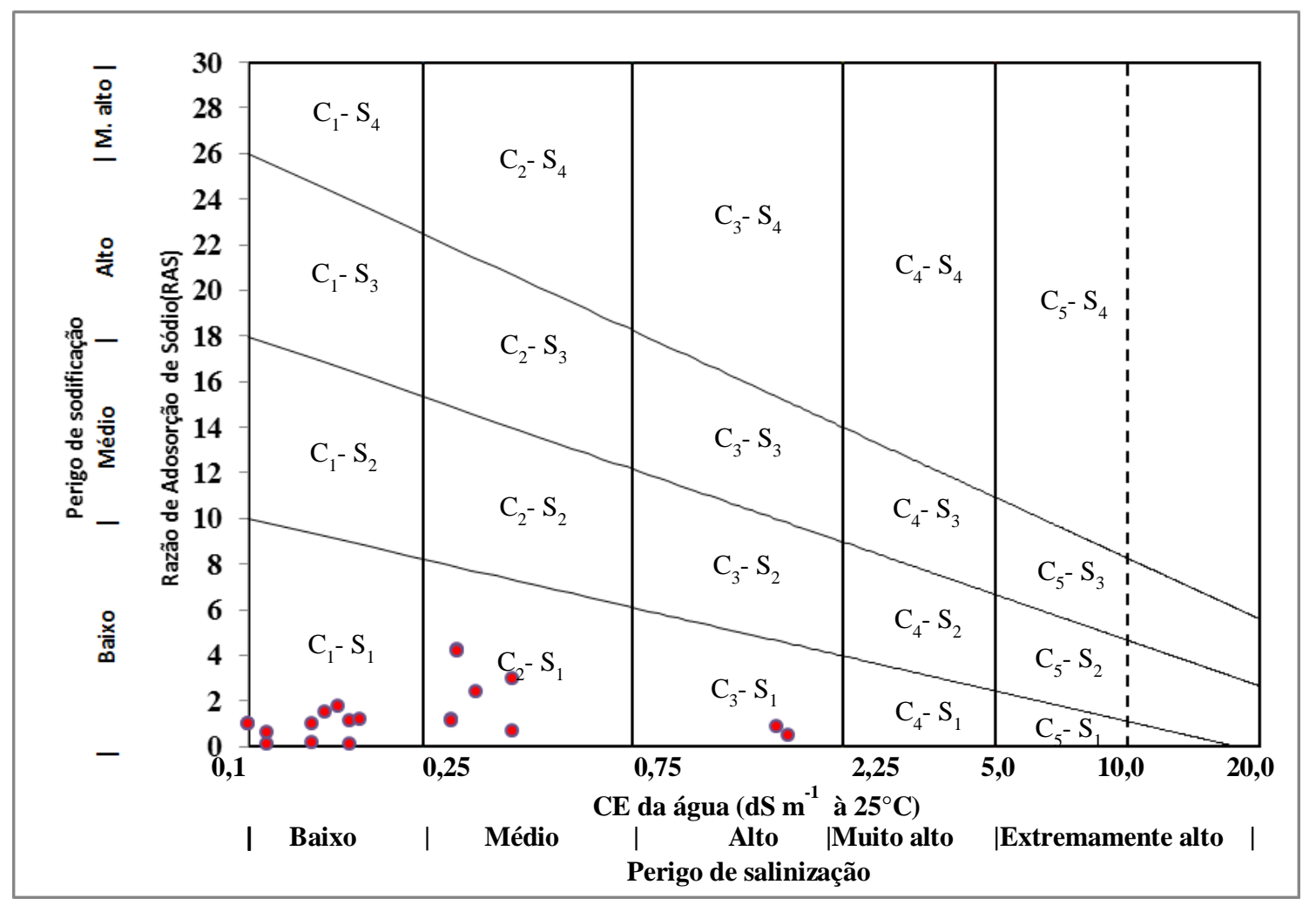

Figura 4- Diagrama de classificação de águas para irrigação da USSL: classificação das águas de dessalinizadas Fonte: Autor (2016) das comunidades rurais do Oeste Potiguar nos 4 períodos

O problema deste dessalinizador nesta comunidade parece ser histórico. Cosme (2011), realizou um estudo nessa comunidade e observou valores de CE da água dessalinizada em $0,63 \mathrm{dSm}^{-1}$, e um elevado valor da RAS da água de 31,15 $\left(\operatorname{mmol}_{\mathrm{C}} \mathrm{L}^{-1}\right)^{1 / 2}$, sendo classificada como $\mathrm{C}_{2} \mathrm{~S}_{4}$. Anders (2013), em sua pesquisa encontrou valores de $\mathrm{CE}_{\mathrm{a}}$ de $1,2 \mathrm{dSm}^{-1}$ e RAS de $0,3\left(\mathrm{mmol}_{\mathrm{c}} \mathrm{L}^{-1}\right)^{1 / 2}$ classificando-a em $\mathrm{C}_{3} \mathrm{~S}_{1}$, alto risco de salinidade e moderada restrição de uso. Neste caso, uma possível ineficiência da membrana seletiva do dessalinizador, pode ser uma das causas disto, ou mesmo a não realização de manutenção adequada e limpeza periódica das membranas, o que poderia ser melhorado com a redução do intervalo das manutenções. Comparando-se os quatro períodos estudados, verificou-se que no período $\mathrm{P}_{2}$ (fevereiro/março), teoricamente, quando iniciam-se as chuvas da região, as análises de água apresentam maiores concentrações de sais, afetando significativamente a classificação e suas restrições de uso. Certamente o lençol freático em que a águas destes poços são capturadas, não teve influência direta das precipitações pluviais, ou seja, ainda não são intensas e nem apresentam volume suficiente para recarga destes mananciais. As exceções foram às águas dessalinizadas das comunidades Lagoa Rasa e Alagoinha, que se mantiveram na classificação de mais baixa salinidade $\mathrm{C}_{1} \mathrm{~S}_{1}$, com $\mathrm{CE}_{\mathrm{a}}$ de 0,08 e 0,10 $\mathrm{dSm}^{-1}$; RAS de 0,5 e $1,0\left(\operatorname{mmol}_{\mathrm{c}} \mathrm{L}^{-1}\right)^{1 / 2}$, respectivamente (Tabela 4 ). 
Tabela 4 - Análise química da água dessalinizada das comunidades rurais em diferentes períodos

\begin{tabular}{|c|c|c|c|c|c|c|c|c|c|}
\hline \multirow{2}{*}{ Localidade } & \multirow{2}{*}{ Período } & $\mathrm{pH}$ & CE & $\mathrm{Na}^{+}$ & \multicolumn{5}{|l|}{$\mathrm{Cl}^{-}$} \\
\hline & & (água) & $\mathrm{dS} \mathrm{m}^{-1}$ & $-\operatorname{mmol}_{\mathrm{c}} \mathrm{L}^{-1}$ & 1 - & RAS & USSL $^{-1}$ & $\mathrm{~S}^{2}$ & $\mathrm{~T}^{3}$ \\
\hline \multirow{4}{*}{ Lagoa Rasa } & P1 & 6,85 & 0,01 & 0,19 & 0,60 & 0,9 & C1S1 & S3 & $\mathrm{T} 1$ \\
\hline & P2 & 7,00 & 0,08 & 0,15 & 0,20 & 0,5 & C1S1 & S3 & $\mathrm{T} 1$ \\
\hline & P3 & 6,70 & 0,03 & 0,26 & 0,60 & 0,80 & C1S1 & S3 & $\mathrm{T} 1$ \\
\hline & P4 & 5,33 & 0,03 & 0,18 & 0,80 & 0,46 & C1S1 & S3 & $\mathrm{T} 1$ \\
\hline \multirow{4}{*}{ EMA } & P1 & 7,66 & 0,10 & 0,40 & 0,60 & 1,0 & C1S1 & S3 & $\mathrm{T} 1$ \\
\hline & P2 & 6,44 & 1,60 & 0,40 & 0,60 & 0,9 & C3S1 & $\mathrm{S} 1$ & $\mathrm{~T} 1$ \\
\hline & P3 & 7,30 & 0,07 & 0,35 & 1,20 & 0,38 & C1S1 & S3 & $\mathrm{T} 1$ \\
\hline & P4 & 6,97 & 0,08 & 0,48 & 1,40 & 0,60 & C1S1 & S3 & $\mathrm{T} 1$ \\
\hline \multirow{4}{*}{$\begin{array}{l}\text { Alagoinha } \\
\text { (Mossoró) }\end{array}$} & P1 & 7,52 & 0,17 & 0,67 & 0,80 & 1,1 & C1S1 & S3 & $\mathrm{T} 1$ \\
\hline & P2 & 7,15 & 0,10 & 0,66 & 0,80 & 1,0 & C1S1 & S3 & $\mathrm{T} 1$ \\
\hline & P3 & 7,20 & 0,11 & 0,67 & 1,00 & 0,64 & C1S1 & S3 & $\mathrm{T} 1$ \\
\hline & P4 & 6,80 & 0,15 & 0,83 & 1,60 & 1,52 & C1S1 & S3 & $\mathrm{T} 1$ \\
\hline \multirow{4}{*}{ Boa Fé } & P1 & 7,36 & 0,33 & 1,50 & 2,00 & 2,4 & C2S1 & $\mathrm{S} 2$ & $\mathrm{~T} 1$ \\
\hline & P2 & 7,00 & 0,40 & 2,02 & 2,20 & 3,0 & C2S1 & $\mathrm{S} 2$ & $\mathrm{~T} 1$ \\
\hline & P3 & 7,00 & 0,30 & 2,84 & 4,20 & 4,23 & C2S1 & S3 & $\mathrm{T} 2$ \\
\hline & P4 & 6,53 & 0,30 & 2,08 & 3,20 & 4,16 & C2S1 & S3 & $\mathrm{T} 2$ \\
\hline \multirow{4}{*}{ Jacu } & P1 & 7,44 & 0,29 & 0,70 & 1,00 & 1,2 & C2S1 & $\mathrm{S} 2$ & $\mathrm{~T} 1$ \\
\hline & P2 & 6,44 & 0,29 & 0,70 & 2,00 & 1,1 & C2S1 & $\mathrm{S} 2$ & $\mathrm{~T} 1$ \\
\hline & P3 & 8,20 & 0,14 & 0,11 & 1,60 & 0,15 & C2S1 & S3 & $\mathrm{T} 1$ \\
\hline & P4 & 5,90 & 0,18 & 0,90 & 2,60 & 1,17 & C1S1 & S3 & $\mathrm{T} 1$ \\
\hline \multirow{4}{*}{ Juazeiro } & P1 & 6,98 & 0,14 & 0,32 & 0,80 & 1,0 & C1S1 & S3 & $\mathrm{T} 1$ \\
\hline & P2 & 6,72 & 1,70 & 0,23 & 0,80 & 0,5 & C3S1 & $\mathrm{S} 1$ & $\mathrm{~T} 1$ \\
\hline & P3 & 6,80 & 0,07 & 0,53 & 1,20 & 0,69 & C1S1 & S3 & $\mathrm{T} 1$ \\
\hline & P4 & 5,95 & 0,06 & 0,39 & 1,40 & 0,78 & C1S1 & S3 & $\mathrm{T} 1$ \\
\hline \multirow{4}{*}{$\begin{array}{c}\text { Alagoinhas } \\
\text { (P. dos Ferros) }\end{array}$} & P1 & 7,22 & 0,16 & 0,58 & 0,60 & 1,8 & C1S1 & S3 & $\mathrm{T} 1$ \\
\hline & P2 & 7,03 & 0,40 & 0,66 & 2,00 & 0,7 & C2S1 & $\mathrm{S} 2$ & $\mathrm{~T} 1$ \\
\hline & P3 & 7,00 & 0,11 & 0,08 & 0,80 & 0,08 & C1S1 & S3 & $\mathrm{T} 1$ \\
\hline & P4 & 7,03 & 0,17 & 0,08 & 1,20 & 0,12 & C1S1 & S3 & $\mathrm{T} 1$ \\
\hline
\end{tabular}

${ }^{1}$ Diagrama de classificação de águas para irrigação da USSL (Richards, 1954).

${ }^{2}$ Riscos de problemas de infiltração no solo causados pela sodicidade da água (Ayers \& Westcot, 1999).

${ }^{3}$ Riscos de toxicidade as plantas por íons de $\mathrm{Na}^{+}$ou $\mathrm{Cl}^{-}$na água de acordo com o modo de aplicação (Ayers \& Westcot, 1999).

Fonte: Autor (2016)

Verificando o potencial hidrogeniônico $(\mathrm{pH})$ das águas dessalinizadas das comunidades nos quatro períodos, constatou-se que há uma redução de $\mathrm{pH}$ para quase todas as amostras quando se compara com as águas brutas em cada respectivo período. Do total das amostras, $46 \%$ têm $\mathrm{pH}$ abaixo de 7,00, destacando o período $\mathrm{P}_{4}$, em que seis comunidades tiveram suas águas dessalinizadas moderadamente ácidas, com o menor valor de 5,33 em Lagoa Rasa. Isso certamente colaborado pela redução de carbonatos $\left(\mathrm{CO}_{3}{ }^{2-}\right)$ e bicarbonatos $\left(\mathrm{HCO}_{3}{ }^{-}\right)$ retidos durante o processo de dessalinização pelas membranas.

De acordo com a resolução da Portaria $n^{0}$ 2914/2011 - MS, pH de água abaixo de 6,00 não está nos padrões para consumo humano, precisando de algum tratamento para correção. Neste contexto, os 
moradores das comunidades monitoradas, em alguns períodos do ano ingerem água imprópria para consumo.

No entanto, avaliando a RAS e a $\mathrm{CE}_{a}$ para riscos de problemas de infiltração no solo causados pela sodicidade da água, proposto por Ayers \& Westcot (1999), percebe-se que há riscos severos $\left(\mathrm{S}_{3}\right)$ para $75 \%$ das amostras coletadas, $18 \%$ riscos crescentes e apenas $7 \%$ sem riscos. O elevado número de amostras com riscos severos ou crescentes é resultante da baixa CE da água, que permite uma maior ação do sódio (RAS) quando há baixa quantidade de outros sais na água ao serem aplicados no solo.

Verificando os níveis dos íons de sódio e cloreto das amostras de água dessalinizada, do ponto de vista dos riscos de toxicidade às plantas, conforme também Ayers \& Westcot (1999), para uso na irrigação (superfície ou aspersão), 93\% das amostras não apresentam nenhum risco de toxicidade ao serem usadas por essas técnicas de irrigação e apenas 7\% apresentam risco moderado.

De uma forma geral, isto evidencia a eficiência dos sistemas de dessalinização das comunidades, produzindo água de boa qualidade para alguns fins, principalmente para consumo humano, considerando que as águas dessalinizadas estão dentro dos limites de cloreto recomendado pela Portaria $\mathrm{n}^{\circ}$ 2914/2011 - MS, cujo limite é de $250 \mathrm{mg} \mathrm{L}^{-}$ 1 . Porém, considerando o aspecto do risco de sodicidade do solo, citado anteriormente, devendo-se utilizar com técnicas adequadas as particularidades locais, caso seja usado via irrigação, como a fertirrigação.

\section{3 Águas de rejeito}

De conformidade com os resultados das análises químicas e os correspondentes limites de classificação, as classes de águas para a irrigação ficaram assim definidas para as amostras de água de rejeito das comunidades ao longo dos períodos (Tabela 5). Na Figura 5, pode-se observar que as águas de rejeito da dessalinização das comunidades, em sua maioria, obtiveram classificações semelhantes com as das águas dos poços (bruta). Com relação à salinidade, 93\% das amostras de água de rejeito se classificaram como $\mathrm{C}_{3}$ ou $\mathrm{C}_{4}$, ou seja, praticamente todas as comunidades tiveram seus rejeitos classificados dentro dessas duas classes, exceto no período $\mathrm{P}_{3}$ (junho/julho), em que Jacu e Alagoinha (Pau dos Ferros), classificaram-se com $\quad \mathrm{C}_{1}$ e $\quad \mathrm{C}_{2}$, respectivamente.

Cosme (2011) em sua pesquisa encontrou valores próximos ao deste trabalho, em que mais de $90 \%$ das amostras de água de rejeito dos poços das comunidades rurais do município de Mossoró-RN, se enquadravam nas classes $C_{3}$ ou $C_{4}$. Para Anders (2013), das amostras de rejeito analisadas, 60\% apresentaram risco de salinização do solo por irrigação muito alto $\mathrm{C}_{4}$, água não apropriada para irrigação em condições normais, podendo ser usada em condições especiais de solos com boa drenagem, desde que se aplique lâmina de lixiviação adequada e uso de culturas tolerantes a sais (ALMEIDA, 2010). Os 40\% restantes, ficaram na classe $\mathrm{C}_{3}$, com risco alto de contaminação do solo por excesso de sais solúveis. Segundo Almeida (2010) esta água não pode ser usada em solos que tenham drenagem deficiente e mesmo em solos com boa drenagem pode necessitar de práticas especiais para controle da salinidade, sendo indicado uso de espécies bastante tolerante a sais.

Em Alagoinhas (P. dos Ferros) no $\mathrm{P}_{2}$ (fevereiro/março), o rejeito apresentou valores excessivamente elevados dos parâmetros físico-químicos, muito superior a água bruta. Provavelmente por problemas de manutenção do sistema, limpeza inadequeda, ocasionando, por vezes, encrustamento no equipamento e, consequentemente, aumento da concentração dos sais da água.

As comunidades EMA e Boa Fé tiveram suas águas de rejeito em todos os períodos de coleta classificadas na classe $\mathrm{C}_{4}$. A CE média destas águas, considerando os quatro períodos, foram de aproximadamente de 2,84 e $8,14 \mathrm{dS} \mathrm{m}^{-1}$, respectivamente. Para 
se ter uma ideia, de um modo geral, a quantidade de sais depositada no solo da região Médio Oeste Potiguar, pelo processo de dessalinização, considerando apenas o período $\mathrm{P}_{2}$ (fevereiro/março), a $\mathrm{CE}_{\mathrm{a}}$ média das comunidades neste período foi de $5,7 \mathrm{dS} \mathrm{m}^{-1}$, isto é, 3,6g de sais por litro, aproximadamente. O impacto que essas águas causam no solo, sem qualquer controle ou manejo para mitigar seus efeitos, tornará muito em breve os solos receptores destas comunidades desertificados pelo processo evolutivo da salinização.

Tabela 5 - Análise química da água de rejeito das comunidades rurais em diferentes períodos

\begin{tabular}{|c|c|c|c|c|c|c|c|c|c|}
\hline \multirow{2}{*}{ Localidade } & \multirow{2}{*}{ Período } & $\mathrm{pH}$ & CE & $\mathrm{Na}^{+}$ & \multicolumn{5}{|l|}{$\mathrm{Cl}^{-}$} \\
\hline & & (água) & $\mathrm{dS} \mathrm{m}^{-1}$ & - -mmol$_{\mathrm{C}}$ & $J^{-1}-$ & RAS & $\mathrm{USSL}^{-1}$ & $S^{2}$ & $\mathrm{~T}^{3}$ \\
\hline \multirow{4}{*}{ Lagoa Rasa } & $\mathrm{P} 1$ & 7,63 & 1,48 & 10,24 & 5,00 & 6,0 & C3S2 & S1 & $\mathrm{T} 3$ \\
\hline & P2 & 8,00 & 1,80 & 13,01 & 7,40 & 6,9 & C3S1 & S2 & $\mathrm{T} 3$ \\
\hline & P3 & 7,70 & 1,15 & 8,93 & 6,20 & 5,20 & C3S1 & S2 & $\mathrm{T} 2$ \\
\hline & $\mathrm{P} 4$ & 7,60 & 1,31 & 19,25 & 6,00 & 10,93 & C3S2 & S2 & $\mathrm{T} 3$ \\
\hline \multirow{4}{*}{ EMA } & $\mathrm{P} 1$ & 7,40 & 2,98 & 15,85 & 20,40 & 6,6 & C4S2 & S1 & $\mathrm{T} 3$ \\
\hline & P2 & 7,54 & 3,48 & 19,14 & 18,20 & 7,4 & C4S1 & S1 & T3 \\
\hline & P3 & 7,20 & 2,40 & 48,3 & 14,80 & 19,4 & C4S4 & S2 & T3 \\
\hline & P4 & 7,48 & 2,51 & 46,36 & 16,40 & 18,93 & C4S3 & $\mathrm{S} 2$ & T3 \\
\hline \multirow{4}{*}{$\begin{array}{l}\text { Alagoinha } \\
\text { (Mossoró) }\end{array}$} & $\mathrm{P} 1$ & 7,38 & 1,54 & 4,51 & 8,80 & 1,9 & C3S1 & S1 & $\mathrm{T} 2$ \\
\hline & P2 & 7,76 & 2,00 & 3,64 & 10,20 & 1,4 & C3S1 & S1 & $\mathrm{T} 3$ \\
\hline & P3 & 7,60 & 1,50 & 12,99 & 9,40 & 4,88 & C3S1 & S1 & $\mathrm{T} 3$ \\
\hline & P4 & 7,26 & 1,51 & 10,27 & 9,60 & 3,71 & C3S1 & S1 & $\mathrm{T} 3$ \\
\hline \multirow{4}{*}{ Boa Fé } & P1 & 7,49 & 8,41 & 33,70 & 92,00 & 6,5 & C4S1 & S1 & T3 \\
\hline & P2 & 7,02 & 9,30 & 38,90 & 100,00 & 7,1 & C4S1 & S1 & T3 \\
\hline & P3 & 7,20 & 7,30 & 40,09 & 87,00 & 7,12 & C4S2 & S1 & T3 \\
\hline & $\mathrm{P} 4$ & 7,35 & 7,56 & 72,63 & 82,00 & 12,11 & C4S2 & S1 & T3 \\
\hline \multirow{4}{*}{ Jacu } & $\mathrm{P} 1$ & 7,82 & 6,23 & 29,33 & 60,60 & 7,8 & C4S1 & S1 & T3 \\
\hline & P2 & 7,39 & 6,30 & 29,87 & 56,00 & 7,9 & C4S1 & S1 & T3 \\
\hline & P3 & 7,50 & 0,22 & 1,97 & 3,40 & 1,56 & C1S1 & $\mathrm{S} 2$ & $\mathrm{~T} 2$ \\
\hline & P4 & 7,30 & 4,24 & 30,93 & 61,00 & 6,96 & C4S1 & S1 & T3 \\
\hline \multirow{4}{*}{ Juazeiro } & P1 & 7,28 & 2,97 & 6,96 & 27,00 & 2,1 & C4S1 & S1 & T3 \\
\hline & P2 & 7,06 & 3,20 & 9,09 & 27,60 & 2,7 & C4S1 & S1 & T3 \\
\hline & P3 & 7,50 & 1,95 & 15,20 & 19,40 & 5,30 & C3S1 & S1 & T3 \\
\hline & P4 & 7,03 & 2,70 & 15,89 & 37,00 & 4,07 & C4S1 & S1 & $\mathrm{T} 3$ \\
\hline \multirow{4}{*}{$\begin{array}{c}\text { Alagoinhas } \\
\text { (P. dos Ferros) }\end{array}$} & $\mathrm{P} 1$ & 7,43 & 2,24 & 8,49 & 11,60 & 3,1 & C3S1 & S1 & $\mathrm{T} 3$ \\
\hline & P2 & 6,67 & 13,80 & 51,33 & 112,00 & 8,4 & C4S1 & S1 & $\mathrm{T} 3$ \\
\hline & P3 & 7,90 & 0,71 & 15,99 & 6,80 & 7,90 & C2S1 & S2 & T3 \\
\hline & P4 & 7,53 & 1,74 & 26,36 & 8,20 & 11,19 & C3S2 & S2 & T3 \\
\hline
\end{tabular}

${ }^{1}$ Diagrama de classificação de águas para irrigação da USSL (Richards, 1954)

${ }^{2}$ Riscos de problemas de infiltração no solo causados pela sodicidade da água (Ayers\&Westcot, 1999) ${ }^{3}$ Riscos de toxicidade as plantas por íons de $\mathrm{Na}^{+}$ou $\mathrm{Cl}^{-}$na água de acordo com o modo de aplicação (Ayers\&Westcot, 1999).

Fonte: Autor (2016) 


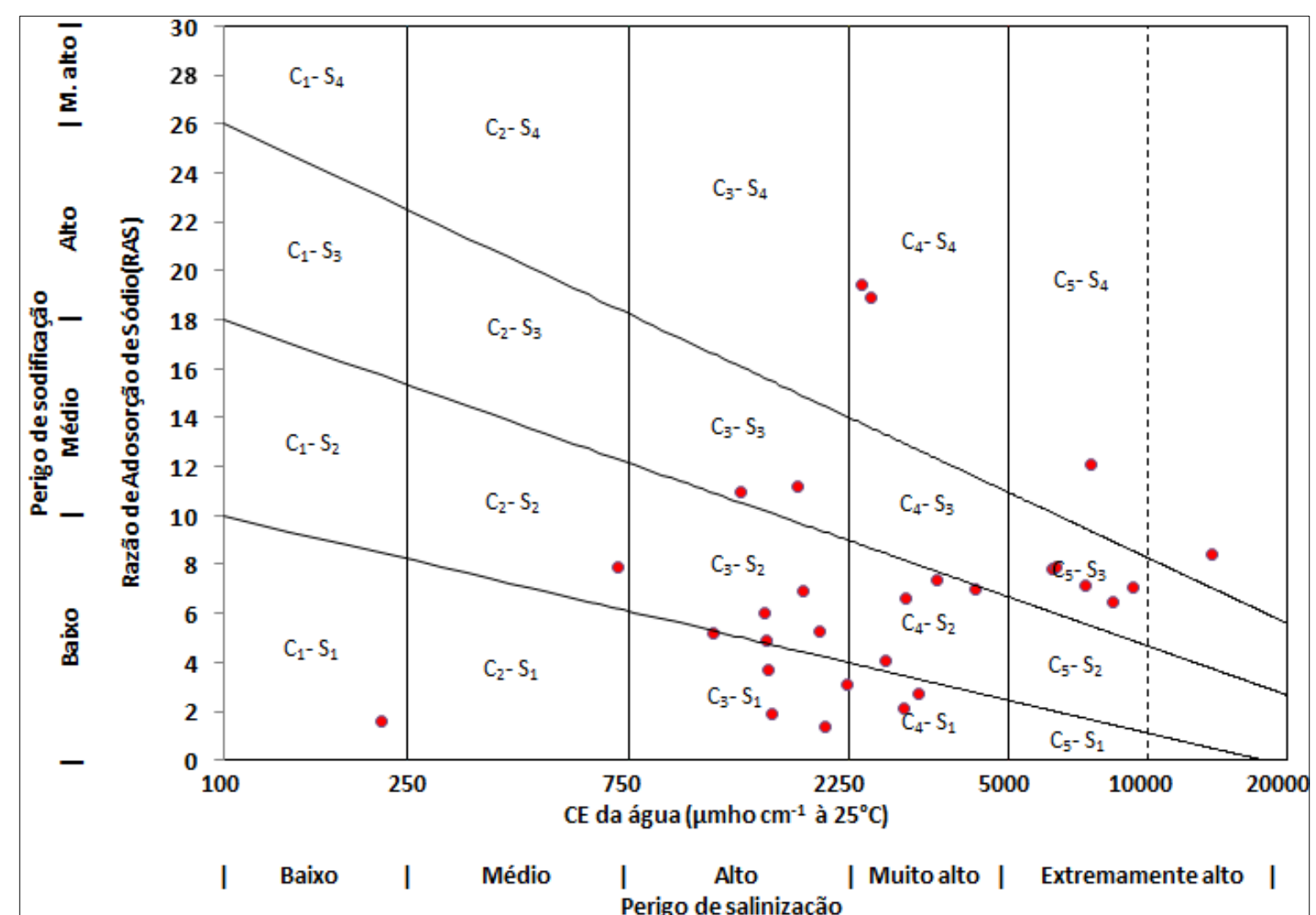

Figura 5- Diagrama de classificação de águas para irrigação da USSL: classificação das águas de rejeito das comunidades rurais do oeste potiguar nos 4 períodos

Fonte: Autor (2016)

As águas dos poços das comunidades apresentaram alterações significativas das variáveis ao longo dos períodos estando correlacionado com os dados médios de precipitação pluvial das respectivas regiões, ao mesmo tempo que as águas de rejeito obtiveram comportamento semelhante. Esse comportamento é coerente, visto que o processo de dessalinização deve gerar um rejeito proporcional à salinidade da água do poço. Ainda que no intervalo de outubro de 2013, início da campanha de coletas, a outubro de 2014, tenham ocorrido precipitações abaixo das médias anuais dos municípios da região, fato esse que vem ocorrendo há alguns anos, interveio nas características avaliadas das águas, principalmente na CE e RAS.

De acordo com essa classificação proposta, 71\% das amostras de água de rejeito das comunidades monitoradas nessa pesquisa, não apresentam, à princípio, risco de problemas de infiltração $\left(\mathrm{S}_{1}\right)$ caso sejam aplicadas no solo. Esta qualificação deve-se ao fato dessas amostras apresentarem elevada CE pela presença de outros sais diferentes do sódio, que proporcionam floculação das micelas do solo, efeito inverso ao do sódio.

Contudo, deve-se compreender que os riscos não podem ser estimados apenas pelos parâmetros físico-químicos da água, mas também pelas características do solo (classificação textural e classe de solo) e manejo empregado. As demais amostras, $29 \%$, foram classificadas como $\mathrm{S}_{2}$, ou seja, de risco crescente, evidenciando dentro desse percentual, a comunidade Lagoa Rasa do município de Apodi, nos períodos $\mathrm{P}_{2}, \mathrm{P}_{3}$ e $\mathrm{P}_{4}$. Já quanto à toxicidade das águas de rejeito da dessalinização quanto aos íons de sódio ou cloreto, 89\% dessas águas qualificaram-se como de risco severo $\mathrm{T}_{3}$, se forem aplicadas via irrigação e apenas $11 \%$ do rejeito salino classificadas como $\mathrm{T}_{2}$, risco moderado. Isto fica visível em simples observação sobre a área de eliminação e influência do rejeito, em que praticamente não há vegetação incidente que tolere condições 
tão elevadas de estresse salino e toxicidade por àqueles íons.

Ao analisar o potencial hidrogeniônico (pH) das águas de rejeito das comunidades nos quatro períodos, verificouse que quase todas as amostras apresentarem valores acima de 7,00, registrando a exceção, Pau dos Ferros, sendo a mais baixa e a mais alta em Lagoa Rasa, com pH 7,02 e 8,00, respectivamente. Isto é, as águas de rejeito foram as que apresentam maiores valores de $\mathrm{pH}$ quando comparada com as outras águas do processo de dessalinização, a água bruta e a dessalinizada. Devendo este fato ao aumento de carbonatos $\left(\mathrm{CO}_{3}{ }^{2-}\right)$ e bicarbonatos $\left(\mathrm{HCO}_{3}{ }^{-}\right)$ encontrados facilmente nas águas do aquífero jandaíra, de origem calcária, onde os poços das comunidades rurais captam, que removidos da água bruta se concentram na água de rejeito.

Para Dias et al. (2003), a avaliação dos riscos de salinização de uma área mediante a água de irrigação não poderá ser realizada simplesmente pela qualidade da água, pois seus efeitos dependem das características do solo, da tolerância das culturas exploradas, das condições climáticas locais e manejo da irrigação e drenagem, além das características físico-químicas do solo. Assim, apesar da importância do estudo da qualidade da água, deve-se ressaltar que ela é tão somente um dos fatores e que não é razoável generalizar um único sistema de classificação de água que possa ser usado em todas as situações.

\section{CONCLUSÕES}

Quanto ao risco potencial de salinização do solo pela técnica da irrigação, constatou-se que $49 \%$ das águas de poços foram classificadas na classe $\mathrm{C}_{3}$, sendo $42 \%$ como $\mathrm{C}_{3} \mathrm{~S}_{1}$ e $7 \%$ em $\mathrm{C}_{3} \mathrm{~S}_{2}$.

De um modo geral, foi evidenciando a eficiência dos sistemas de dessalinização das comunidades, em que, $68 \%$ do total das amostras durante os quatro períodos estudados estão na classe de classificação $\mathrm{C}_{1} \mathrm{~S}_{1} ; 25 \%$ na classe $\mathrm{C}_{2} \mathrm{~S}_{1} \mathrm{e}$; apenas $7 \%$ na classe $\mathrm{C}_{3} \mathrm{~S}_{1}$.
Com relação ao rejeito gerado, 93\% das amostras de água de rejeito das comunidades se classificaram como $\mathrm{C}_{3}$ ou $\mathrm{C}_{4}$ nos quatro períodos de coleta, ou seja, águas de alto ou extremamente alto risco de salinização.

Referente aos riscos de toxicidade as plantas por íons de $\mathrm{Na}^{+}$ou $\mathrm{Cl}^{-}, 64 \%$ das amostras de água de poço foram classificadas como $\mathrm{T}_{3} \mathrm{e}$ do rejeito salino $88 \%$ foram classificadas em $\mathrm{T}_{3}$, isto é, de risco severo de toxicidade às plantas.

Em 71\% das amostras de água de rejeito, não apresentam, a princípio, risco de problemas de infiltração $\left(\mathrm{S}_{1}\right)$ caso sejam aplicadas no solo. Esta qualificação deve-se ao fato dessas amostras apresentarem elevada CE pela presença de outros sais diferentes do sódio, que proporcionam floculação das micelas do solo, efeito inverso ao do sódio.

\section{REFERÊNCIAS}

AGÊNCIA NACIONAL DE ÁGUAS - ANA. A questão da água no Nordeste. Brasília, DF: CGEE. 432 p. 2012.

ALMEIDA, O. A. Qualidade da água de irrigação. EMBRAPA Cruz das Almas, 2010, 234p. Disponível em: http://www.cnpmf.embrapa.br/publicacoes/livr o qualidade agua.pdf. Acesso em: 20 junho 2016.

AMORIM, M. C. C.; PORTO, E. R.; ARAÚJO, O. J.; SILVA JÚNIOR, L. G. Alternativas de reuso dos efluentes da dessalinização por osmose inversa: evaporação solar e meio líquido para cultivo de tilápiakoina (Oreochromissp.). http://www.cepis.ops-oms.org/indexpor.html

Acesso em: 10 Jul. 2004

ANDERS, C. R. Caracterização química da água de dessalinizadores e dos solos sob a influência do rejeito salino em Mossoró - $\mathbf{R N}$. Dissertação (Mestrado em Ciência do Solo)Universidade Federal Rural do Semi-árido, 2013.

AYERS, R.S.; WESTCOT, D.W. A qualidade da água na agricultura. 2.ed. Campina Grande: UFPB, 1999. 153p. (Estudos FAO: Irrigação e Drenagem, 29). 
BELTRÁN, J. M.; KOO-OSHIMA, S. Water desalination for agricultural applications. Land and water discussion paper 5, Itália, 2006,49p.

CONAMA Na 357/2005 - Dispões sobre a classificação das águas doces, salobras e salinas do Território Nacional. Disponível em: http://www.mma.gov.br/port/conama/legiabre.cf $\underline{\text { m?codlegi=459. }}$. Acesso: em 01 de julho de 2016.

COSME, C. R. Avaliação da qualidade da água proveniente das estações de tratamento de água salobra na zona rural do município de Mossoró-RN. Dissertação (Mestrado emIrrigação e Drenagem) - Universidade Federal Rural do Semiárido, 2011

DIAS, N. S. et al. Prevenção, manejo e recuperação de solos afetados por sais. Piracicaba: ESALQ/USP/LER. 2003.

EMPARN. Monitoramento pluviométrico. Empresa de Pesquisa Agropecuária do Rio Grande do Norte. Disponível em:http://189.124.201.150/monitoramento/monit oramento.php. Acesso: 20 de janeiro de 2016.

FAO. Global Network on integrated soil manegement for sustainable use of salt-affected soils.2006. Disponível em: http://www.fao.org/ag/AGL/agll/spush/intro.htm. Acesso em 23 abril 2015.

HIRATA, R. C. A; FERREIRA, L. M. R. Os aquíferos da Bacia Hidrográfica do Alto Tietê: disponibilidade hídrica e vulnerabilidade à poluição. Revista Brasileira de Geociências. v. 31, n. 1, p. 43-50, março de 2001.

HOLANDA, J. S. de; AMORIM, J. R. A. de; FERREIRA NETO, M. et al. Qualidade da água para irrigação. In: GHEYI, H. R.; DIAS, N. da S.; LACERDA, C. F. de Manejo da salinidade na agricultura: estudos básicos e aplicados. Fortaleza: INCTSal/CNPq, 2010. cap. 4, p. 41-60.
LAMARCA, G; VETTORE, M. Desigualdades relacionadas à distribuição de água no Nordeste. 2013. Disponível em: http://dssbr.org/site/2013/05/desigualdadesrelacionadas-a-distribuicao-de-agua-nonordeste/.Acesso em: 12 outubro 2016.

MEDEIROS, J. F. Qualidade da água de irrigação e evolução da salinidade nas propriedades assistidas pelo “GAT" nos estados do RN, PB e CE. Dissertação (Mestrado) - UFPB/CCT/DEAg, Campina Grande, 1992.

OLIVEIRA, A. M. Potencial de utilização agrícola das águas "salobras" e residuárias da dessalinização por osmose reversa. Dissertação (Mestrado em Ciência do Solo) - Universidade Federal Rural do Semi-Árido, 2011.

RICHARDS, L.A. (ed.) Diagnosis and improvement of saline and alkali soils. Washington D.C.: U.S. Salinity Labratory.,1954. 160p. (USDA.Agriculture Handbook,60).

SEMARH - Secretaria de estado de meio ambiente e dos recursos hídricos - Plano Estadual de Recursos Hídricos. (relatório síntese). Disponível em:http://www.semarh.rn.gov.br/.Acesso em: 25 jan. 2014.

SOARES, T. M. Utilização de aguas salobras no cultivo da alface em sistema hidropônico NFT como alternativa agrícola condizente ao semiárido brasileiro. Tese (Doutorado em Agronomia)- Escola Superior de Agricultura Luiz de Queiroz, 2007. 